\title{
Situated Knowledge of Pathogenic Landscapes in Ghana: Understanding the Emergence of Buruli ulcer through Qualitative Analysis
}

\begin{abstract}
Successfully addressing neglected tropical diseases requires nuanced understandings of pathogenic landscapes that incorporate situated, contexualized community knowledge. In the case of Buruli ulcer (BU), the role of social science is vital to investigate complex humanenvironment interactions and navigate different ways of knowing. We analyze a set of qualitative data from our interdisciplinary project on BU in Ghana, drawing from participatory mapping, focus group discussions, semi-structured interviews, and open-ended survey questions to explore how people in endemic and non-endemic areas see themselves embedded in changing environmental and social landscapes. We pay particular attention to landscape disturbance through logging and small-scale alluvial gold mining. The results from our participatory research underscore the holistic nature of BU emergence in landscapes, encapsulated in partial and incomplete local descriptions, the relevance of collective learning to distill complexity, and the potential of rich qualitative data to inform quantitative landscape-disease models.
\end{abstract}

Key words: Ghana; neglected tropical diseases; Buruli ulcer; situated knowledge; participatory research; pathogenic landscapes; gold mining; social sciences 


\section{Introduction}

At a time when fear and misinformation about uncommon diseases have become a fixture of our global dialogue, the opportunity is ripe to re-evaluate our understanding of health crises as they relate to society as a whole. Buruli ulcer (BU), an aggressive infection that degrades the skin, soft tissue, and bone of affected individuals, represents one such poorly-understood and stigmatized disease. Caused by the bacterium Mycobacterium ulcerans (MU), BU typically begins with painless swelling or a small nodule that, if left untreated, results in large ulcers, most commonly on legs and arms. The bacterium itself secretes a cytotoxin that damages tissues and inhibits immune response. In severe cases, patients are left with extensive scars, deformities, or amputations; in rarer instances, the infection can be fatal. While only 15 countries have actively reported BU cases regularly over the past decade, the World Health Organization (WHO 2014) tracks cases in >30 different countries, predominantly in the tropics. Most cases of BU occur in Africa; the exceptions among high-income countries are Australia and Japan. In 2013 alone, the countries with the highest number of new cases were Côte d'Ivoire $(1,039)$, Ghana (550), and Benin (378), although underreporting is widespread (WHO 2013).

While Mycobacterium ulcerans is from the same family of agents that cause tuberculosis, the mode of transmission for BU is unknown. BU ranks among the WHO's list of 17 neglected tropical diseases (NTDs) along with leprosy, dengue, rabies, and schistosomiasis. Like most other NTDs, BU is an 'infectious disease of poverty' (WHO 2012). NTDs are described as “both drivers and manifestations of poverty and inequality in developing countries" (Bardosh 2014: 1- 
3) reflecting "not only individual risk factors, but larger structural inequalities in access to health services, infrastructure, food security, education, political voice and markets that drive poverty and maintain social and economic exclusion.”

Increasing scientific evidence suggests that environmental factors play important roles in BU transmission. What remains contested is where in the environment MU resides. Hypotheses range from small environmental niches to a wide diversity of environments (see Landier et al. 2014; McIntosh et al. 2014). Potential BU risk areas include settings transformed by deforestation, mining operations, rice cultivation, wetland modification, human settlement near water, the damming of streams, irrigation systems, and flooding (Hausermann et al. 2012; Wu et al. 2015). Organisms, including aquatic insects (Portales et al. 2009), non-insect aquatic invertebrates (Benbow et al. 2008), vertebrates such as fish and amphibians (Willson et al. 2013), and certain terrestrial biting insects (Merritt et al. 2010) may serve as hosts for MU within aquatic and nearby terrestrial environments. Recent research indicates an association of BU transmission with deep punctures or lacerations, rather than existing wounds, again suggesting insect vectors (Williamson et al. 2014).

In this paper, we contribute to emerging perspectives on NTDs by exploring human-environment interactions in the context of BU in Ghana, namely by expanding understandings of 'pathogenic landscapes' (Lambin et al. 2010) to include contextual community knowledge. We analyze a set of qualitative data, drawing from participatory mapping, focus group discussions, semistructured interviews, and open-ended survey questions to explore how people in endemic and non-endemic areas see themselves embedded in changing environmental and social landscapes. 
We are particularly interested in landscape disturbance through logging and small-scale gold mining. This situated knowledge approach, being local and embodied, allows us to gauge how such positioning shapes particular sets of knowledge, practices, and behaviors. Our aim is to underscore the role of social science and place-based understandings of disease emergence and show the need for navigating different ways of knowing in a larger interdisciplinary investigation. By employing qualitative network models, we aim to unpack the 'black box' of complex social-ecological systems studies that underpin interdisciplinary research (Pujadas Botey et al. 2014).

\section{Types of knowledge approaches to infectious disease emergence}

\subsection{Landscape-level approaches}

Recent studies in disease ecology, particularly those of infectious diseases, have emphasized the complex linkages between land-use/land-cover change, climatic change, disease vectors, and people's activities. These approaches focus on the interaction between altered or disturbed landscapes and humans as drivers for increased risk, generating concepts such as 'unhealthy landscapes' (Patz et al. 2004) and 'pathogenic landscapes' (Lambin et al. 2010). Lambin et al. (2010) suggest a dynamic view of such 'pathogenic landscapes' that highlights spatial and temporal interactions between agents (vectors, animal hosts, human hosts, multiple habitats and land use) at multiple scales, including preferred habitats of vectors and hosts at the natural community level and the interaction of humans with these terrains of risk at the population level. 
In the case of BU, examining spatial and temporal variations in disease incidence across heterogeneous landscapes allows for identifying the spatial and temporal aspects of transmission. Landier et al. (2014) combine BU case data with land-use/land-cover information from remotelysensed imagery and topographic data for Cameroon. Their results illustrate an intricate mix of endemic and non-endemic villages, suggesting highest BU risk in landscapes with abundant wetlands and forested areas modified through clearing and agricultural use. In Victoria, Australia, van Ravensway et al. (2012), using network analysis coupled with hierarchical modeling, find highest risk at low elevations with forested land cover, and a sequence of warm and wet conditions followed by a dry period. Most recently, Wu et al. (2015) demonstrated the close linkage between BU and mining and agricultural disturbance in Ghana.

Despite significant advances in quantitatively assessing and modeling such 'pathogenic landscapes,' these approaches have been predominantly expert-led, quantitative, and top-down. The advantage of such spatial-temporal analyses is that they allow for identifying emergent behaviors at higher levels (e.g. incidence of BU in a particular region or country). The disadvantage is that, despite fine-grained pictures of spatial heterogeneity, at-risk activities often remain grossly generalized, devaluing the pathology that BU victims and others associate with the landscapes in which they live and the experiences that result from day-to-day interactions. This gap limits the exploration of complex positive and negative feedbacks between the social and the ecological that govern system resilience (Cumming et al. 2015). It also hampers the ability to use qualitative information in interdisciplinary studies to better understand disease risk. 


\subsection{Situated knowledge approaches}

Expanding observations to include people's lived experiences requires an appreciation for the complementarity of different ways of knowing (Leach \& Scoones 2013). Research and prevention programs on NTDs have been criticized for neglecting social and contextual drivers (e.g. Allotey et al. 2010; Bardosh 2014). Combining multiple models, modeling expertise, and sources of evidence has proven useful, for example, in the context of zoonotic diseases, such as Ebola and H5N1. Such a combination is best achieved when embedded in dialogic processes across distinct datasets and expertise, and when framing assumptions, system descriptions, and cultural perspectives are deliberated, rather than merely integrated. Dialogue between anthropologists and epidemiologists, for instance, overcame narrow epistemological assumptions and led to more nuanced understandings of human behavior and disease emergence (Trostle \& Sommerfeld 1996). This process of navigating approaches and data between multiple ways of knowing opens up space for contextual relevance. In addition, incorporating lay experiences in disease studies can add new insights into complex disease ecologies.

Participatory epidemiology (e.g. Catley et al. 2012), and participatory geographies of disease more generally (e.g. Leung et al. 2004), have increasingly demonstrated the value of collaborating with lay people in epidemiological studies to foster the co-production of knowledge. Participation in health research typically entails processes of action and reflection, with and by local people, acknowledging human agency and power differentials (Cornwall and Jewkes 1995). Recent participatory efforts that address NTDs include, for instance, community 
mapping of dengue risk in Malaysia (Dickin et al. 2014) and community knowledge of Chagas disease in Mexico (Rosecrans et al. 2014).

We use the term 'situated knowledge' to underscore the importance of lived experiences of people in day-to-day interactions with pathogenic landscapes, and to encourage inclusion and joint reflection relevant for investigating complex disease emergence. The term 'situated knowledge' was introduced by Donna Haraway $(1986,1991)$ to emphasize the position of subjects, including researchers themselves, and unequal power relations in the production of knowledge. Following Haraway, subjective perspectives and embodied experiences combine to produce particular ways of knowing that are never as objective and detached as western science has long claimed. Haraway stresses that all knowledge is inevitably partial and incomplete. Lived experiences constitute an important part of situated knowledge, providing a contextualized and grounded view that adds to a "richer, better account of a world" (Haraway 1991: 187). These experiences need to be understood as embedded in and shaped by language, culture, and social change, as demonstrated in Nichter's (1987) ethnography on the ways rituals, cosmology, and land reform shape Kyasanur forest disease in India or Follér's (2001) human ecology of cholera in the Amazon, reminding us no knowledge exists in isolation. Although local knowledge is often place-specific, it is socially constructed and contextualized, blurring contested boundaries between local/global, modern/scientific and traditional/indigenous (Nygren 1999).

Without either romanticizing or appropriating the views and experiences of people who live and work in at-risk areas, such a situated perspective seems highly valid for examining diseases in which transmission has remained unknown, and where underreporting, misconceptions, and 
stigmatization are common. Multiple lenses, we argue, should be brought to bear to resolve the puzzle. A situated lens provides descriptions of common assumptions, diverse views, and possible explanations where the "local" is seen as contextualized "in context and as process" (Bardosh 2014: 10) rather than merely a level of spatial scale. More than 'local' or 'traditional' or 'indigenous' knowledge, situated knowledge appreciates power-laden perspectives and embodied experiences within heterogeneous communities and, thus, can validate place-based knowledges as ways of meaning making outside of dominant discourses. We explore such situated knowledge in the context of BU, listening to ordinary community members and health personnel who share their grounded sense making, shaped by their own beliefs as well as training or awareness raising programs.

Few recent qualitative studies on BU in West Africa focus on local people's understandings of changing landscapes, in contrast to health services for BU control and intervention, decision making, availability and effectiveness of treatment, wound care, and the socio-economic burden on BU-affected households (e.g. Ackumey et al. 2011; Ahorlu et al. 2013). One noteworthy exception is a grounded ethnohistory of pathogenic landscapes in Cameroon by Giles-Vernick et al. (2014). The authors explore shifts in landscapes and land use practices through local narratives of shattered solidarity, social tensions, and loss of 'love,' thereby exposing the social conditions that make people vulnerable to 'incurable wounds' (atom).

\section{Research Setting and Methods}

\subsection{Study area and design}


Reported BU cases in Ghana are predominantly located in the south-central part of the country. This noticeable BU cluster overlaps rather astonishingly with the main areas of gold mining operations (Figure 1). We consider artisanal/small-scale gold mining activities (ASM) and land disturbance typically without rehabilitation as potential key drivers in MU infection. In Ghana, several factors contribute to the creation of 'pathogenic landscapes' in which diseases such as BU can proliferate: macro-economic policies since structural adjustment policies in the 1970s,

resulting in massive land transformation due to mining and logging (e.g. Benhin \& Barbier 2004; Hilson \& Potter 2005); more severe and more frequent extreme rainfall events over the last 20 years (e.g. EM-DAT 2014); and social marginalization in and lacking state support for the ASM sector (e.g. Tschakert and Singha 2007; Hirons 2014).

\section{$\rightarrow$ Figure 1}

The focus of this paper is a small, yet essential part of a larger, interdisciplinary project on the role of land disturbance in the context of BU emergence in Ghana, entitled reBUild. The project adopts a coupled social-ecological systems approach that emphasizes the interplay between social dimensions of disease and landscape disturbance, drawing upon the fields of landscape ecology, geography, community health, hydrogeoscience, and mining engineering. Our team combines surveys among BU cases, match cases, and control cases, mapping activities and focus group discussions, water, soil, and insect sampling, GIS visualizations of people's activity spaces, remote sensing analyses of land use/land cover change, and spatial modeling of potential disease drivers. Here, we focus on two distinct areas with ASM: endemic sites in south-central 
Ghana, including the communities and adjacent hamlets of Pokukrom and Subin (Districts of Upper Denkyira East and West, respectively), characterized by alluvial mining; and non-endemic sites in Kedadwen (southern Ghana, District of Tarkwa- Nsuaem Municipal) and Nangruma (northern Ghana, Mamprugo Moaduri District), with predominantly hard rock mining, where so far no BU cases are reported. The control sites were selected because their climatic, geological, hydrological, and/or socio-economic conditions (i.e. largely poverty-driven ASM) could be conducive to BU emergence in the near future. Unusually heavy rainfall events in northern Ghana, similar to those in 1999-the year a nation-wide active case search resulted in highest number of BU cases during the 90's (Ampadu et al. 2014)—we reasoned, may transform smallscale mining sites like Nangruma into potentially new risk areas for BU.

Between 2010 and 2013, we facilitated a sub-set of participatory activities (see description below, Table 1, and Figures 2 a-c). They generated qualitative data that improved our understanding of a) how project participants in two endemic sites and two non-endemic sites see their interaction with changing environments that may be associated with $\mathrm{BU}$ prevalence; and b) how their social landscape generates particular knowledges, practices, and behaviors around BU. Participatory methods, used in a variety of disciplinary fields including geography, anthropology, and health sciences, are designed to be reflexive and iterative, generate insights that stem from and are useful to local people, address power and status differentials, support mutual learning, and value process over outcomes (Cornwall \& Jewkes 1995). Hence, they are well suited to encourage contextualized understandings and elicit embodied experiences of BU. These participatory methods allowed us to learn from participants' descriptions as valued, 
complementary, and situated knowledge. Subsequently, we used the results to enrich team deliberation and inform social-ecological systems modeling (see Discussion).

The research activities described here (see also Table 1) received IRB ethics approval through the Pennsylvania State University. First, participatory mapping was carried out in three stages at the community-level with interested, volunteering men and women: 1) community mapping to depict features such as roads, rivers, schools, clinics, settlements, forests, plantations, galamsey (informal ASM sites), and perceived 'hotspots' for disease emergence such as rubbish dumps, polluted water, and swampy areas; 2) participatory mapping of land use/land cover change, using the initial community maps and/or Google maps to identify land use changes and disturbances over 20-30 years; and 3) using clay, 3-D models by students, teachers and community members to explore the role of landscape topography in BU disease dynamics. Second, we drew from evidence generated through semi-structured interviews and open-ended survey questions with $\mathrm{BU}$ cases recruited through a BU medical expert on the team and community nurses to further explore their personal stories of contracting BU. Finally, we conducted focus group discussions with BU volunteers and health personnel from local clinics to understand their perceptions of BU emergence. With the exception of pupils in two rural schools, research participants ranged from 18-75 years in age, with varying educational levels and length of residence. Discussions occurred in English and Twi in a complementary way.

$\rightarrow \quad$ Table 1

$\rightarrow$ Figure $2 \mathrm{a}, \mathrm{b}, \mathrm{c}$ 


\subsection{Analysis}

The qualitative data set provided rich descriptions of individuals' understandings of BU in their landscapes, with attention to possible risk factors, the role of land disturbance in $\mathrm{BU}$ prevalence, and practices and beliefs associated with disease emergence. Unlike other grounded approaches to disease emergence, including thick ethnographies, our aim was to pursue rigorous data coding, following a network approach. Thematic network analysis is a systematized approach using qualitative data to extract themes or explanatory variables that relate to the research questions and to weigh pieces of data to develop a coherent body of evidence (Attride-Stirling 2001). We coded each qualitative dataset individually, in multiple rounds, to refine and clarify the emerging themes and possible linkages to BU. The themes represent participants' different lines of thinking about the factors they believe influence BU emergence. Each line of thinking had pieces of evidence (quotes extracted from transcripts, interviews, focus groups, and activity notes). The more pieces of evidence with a distinct theme, the greater weight it represented.

Next, to go beyond descriptive accounts of situated knowledge, we quantified the relationships and strength between emerging salient themes. We used the network software program UCINET 6 (Borgatti et al. 2002) to analyze each site's thematic network and provide metrics to inform subsequent higher-level socio-ecological modeling. The amount of evidence each variable had, the direct number of connections (degree centrality), the position and ability to bridge variables in the network (betweenness), the strength of relationships (weight), and the overall structure of the network were analyzed (Borgatti et al. 2013). Degree centrality was calculated by the amount of direct connections a given theme has with other themes. Centrality measures (betweenness, 
closeness, and eigenvector) were used to compare how each independent theme was indirectly situated in the four networks.

Finally, emerging themes were compared to key variables from the literature (e.g. Hausermann et al. 2012; McIntosh et al. 2014) and remote sensing analyses (Wu et al. 2015) to advance the team's conceptual model of BU emergence in disturbed landscapes, including land-use/coverchange, soil and water, insects, extreme rainfall events and flooding, practices and exposure, and livelihoods/occupation.

\section{Results}

Overall, a total of 18 themes emerged from the rich descriptive data, all representing lay knowledge about BU, landscape changes, and risk factors. We show simple column graphics to illustrate the number of pieces of evidence for each theme, and web-like maps that visualize the connections amongst salient themes. Graphic outputs are complemented with quotes from participants to contextualize meaning.

\subsection{Comprehending individual themes and connections}

The first important result is the dominance of three distinct themes in endemic areas: dirty or stagnant water as the key BU risk factor or exposure variable, mining as the prime landscape 
change driver associated with BU prevalence, and increased awareness about the disease and resulting changes in behavior. Participants, particularly health personnel in the focus groups, felt strongly that dirty or stagnant water was a high risk matter for attracting BU, due to its association with breeding insects, trash, pollutants like DDT, and galamsey sites nearby. "There is more BU [cases] when it is raining, so people are more exposed to stagnant water, including children. Bacteria in the water get into people" (Subin focus group). "When it rains here, there are more black flies and biting insects in general... These insects are close to stagnant water and near/in bushes. Black fly bites are not felt, but rather only noticed after they bite" (Pokokrum focus group).

Having cuts or wounds was seen as a high risk factor when interacting with stagnant or contaminated water bodies, and so was swimming, playing, and doing laundry. Specifically, seasonality of BU exposure and the potential for open wounds to provide infection pathways were seen as having a coupled effect on contracting the disease, "My daughter got it in the rainy season; they were going to a farm when something pricked her and that is when BU developed" (Subin focus group). Participants also explained that during and right after the rainy season stagnant water was everywhere, attracting many insects people cannot avoid, while the dry season brings different insects that may be differently harmful.

The frequent references to mining as a key disturbance factor are remarkable $(59 \%$ and $47 \%$ of single and overlapping counts, respectively). Participants were adamant that BU emergence was linked to galamsey mining, "They get BU because of galamsey mining, a lot get it there at work" (Subin focus group). However, BU statistics do not reveal high BU rates among galamsey miners 
themselves, mainly because they typically do not declare their unregistered (illegal) livelihood when seeking medical help. Participants cited direct exposure to low-quality water in galamsey landscapes, by working there or passing through on the way to farms, and indirect risks, stating "risky water sources travel through landscapes when they flood". One man explained that most galamsey miners were not locals: "Kids go and play in galamsey pits and then they get sick. We sold this land and now we have the issues to deal with" (community mapping, Pokukrom). Along the Subin River, galamsey mining expanded after the closure of a dredging corporation; now "the women are in the river... and washing for the galamsey. Their vaginas come into contact with the water all day" (community mapping, Subin).

Awareness about the disease and possible modes of transmission (direct exposure and insect bites) has been growing in the research areas, largely due to health education campaigns and BU volunteers in endemic communities. People's knowledge about potential transmission mirrored scientific insights into possible transmission pathways, including the role of low-quality and stagnant water, insights that were also presented by team members through educational outreach events at community workshops and school activities. Although more people seek medical help sooner than before, problems with access to care remain as monetary constraints hamper transportation or treatment, coupled with fear of inaccurate diagnosis.

Participants reported changes in behavior at two levels: a) avoiding high-risk areas whenever possible, especially after contracting cuts or wounds, or by wearing protective clothing (e.g. long pants, long-sleeved shirts, and boots); and b) changing behavior after having been infected. The latter was said to be a result of long treatments away from home, and due to physical pain after 
treatment (scars, skin grafting, or amputation) and stigmatization. Stigmatization continues to exist and, according to the discussions, appears higher among women than men, which may explain more counts of 'stay-at-home' as an occupation among women in our total sample (10/67 female compared to $6 / 67$ male among BU cases, in contrast to 1 female and 1 male/60 among match cases). Several participants described situations in which BU victims no longer appear in public due to shame and ridicule or face difficulties finding work. A 20-year old woman explained:

"I stopped schooling after surgery because friends laughed at me; even now if I go out, I have some friends who laugh at me. Moreover, my mates were ahead of me because of the time I stayed out of school in the hospital. I don't go to farm anymore... My first husband has stopped with me [has left me] because of the $B U . .$. He is now married to another woman and that woman came to fight with me and told me the husband stopped with me because of the BU. Two other men left me because of the BU. I struggled to take care of the 3 kids... Now I don't go out at all (semi-structured interview, Pokukrom).

The second noteworthy result is the stark difference in discussed themes between endemic areas (Pokukrom and Subin) and non-endemic areas (Kedadwen and Nangruma), consistently across three main categories (Figure $3 \mathrm{a}$ ac). This result underscores the differential knowledge about linkages between land disturbance, risk factors, and people's practices and behavior. Participants in endemic areas raised not only more themes per category but also more pieces of evidence under each theme. Despite the unequal number of activities and participants between sites (Table 1), the findings point toward the ability of lay people in risk areas, more so than in non- or low- 
risk areas, to elicit potential connections between their changing landscapes and $\mathrm{BU}$ emergence. In the former, the counts indicate roughly 4-5 times as many elicitations for risk factors and land disturbance and 16-28 as many discussion points around practices and beliefs.

$\rightarrow$ Figure 3 (a-c)

Moreover, the complex patterns of disease drivers and protective factors vary substantially between the two areas (Figures 4a-d). The networks for Pokukrom and Subin (endemic) show distinctly more themes (21) and connections between them than the networks from Kedadwen and Nangruma (non-endemic) with only nine themes emerging from the grounded thematic analysis. Despite similar network densities (total number of actual connections divided by the number of potential connections; ranging from 0.3 to 0.4 ) and average distance between any given theme (1.7 to 2.3 steps), the understanding of BU emergence in endemic sites had a greater capacity to bridge different themes. In other words, participants in the endemic locations viewed BU emergence as being highly dependent on several factors that require concurrent examination.

$\rightarrow$ Figure 4 (a-d)

Both Kedadwen and Nangruma, like the endemic sites, gave significant weight to mining activities, in connection with dirty and stagnant water. One man explained: "The Nyani river used to be clean, and now is polluted... people used to swim there but not anymore and the swampy areas near school are now a problem because kids play there... kids bathe in the galamsey pits" (community mapping, Kedadwen). Yet, BU has so far not been reported in these sites, which some in Kedadwen linked to the uneven succession of galamsey activities and forest 
and plantation lands. The key difference between the endemic and non-endemic sites was that, in the former, participants identified clearer connections to insects, agriculture, and flooding events, all of which interact with mining and dirty, stagnant water to form high-risk environments.

\subsection{Making sense of complex relationships}

Even more revealing are the complex relationships that participants, particularly in the endemic sites, saw in debating the emergence of BU, expressed in the high number of overlapping evidence between themes and centrality measures. They did not view identified exposure factors such as water bodies, insects, cuts and wounds, and disturbed landscapes as acting in isolation. Unlike most epidemiological studies that treat risk factors as bounded (e.g. presence/absence of swampy areas), the overlapping pieces of evidence point toward people's understanding of exposure as a complex interweaving of risk factors. For instance, participants explained that mining had cleared forests (temporal succession) and miners now had to cross remaining forests or bush to get to their sites (spatial succession). One health worker suggested that "grasscutters [cane rats] like to swim in water bodies, and maybe, if they are infected, they can affect other water bodies" (Subin focus group). Others noted that BU had been prevalent [in Pokukrom] before galamsey mining started, but in combination with other possible drivers such as insects and flooding, mining was seen as an increasing risk factor.

The essence of people's lay understanding of BU and changing landscapes was situated at the intersection of dirty/stagnant water, gold mining, agriculture, flooding, insects, and bush meat, 
with raised awareness as a protective factor. Figure 5 conveys the aggregated sense of interconnectedness between the various drivers of BU prevalence and emergence, as shared by research participants. The themes are laid out using the spring embedded algorithm; the more central a theme is in the diagram, the more evidence it shares with other themes.

\section{$\rightarrow$ Figure 5}

Despite this rich picture, most participants struggled with identifying where precisely in their landscape MU may be hidden, mainly due to the unknown mode of transmission and lag time between exposure and contraction, and because equal exposure doesn't necessarily result in BU infection. One woman said, "We bathed and drank water from the well together anytime we went to the farm with my three junior siblings, but I was the only person who got the disease" (semistructured interview, Pokukrom).

Finally, centrality measures reveal five core themes: dirty/stagnant water, gold mining, agriculture, insects, and flooding (Table 2), with some noteworthy differences. Gold mining was of high importance for the two non-endemic sites (highest degree centrality and betweenness scores) but only ranked fourth and fifth for the two endemic communities where dirty/stagnant water showed the highest betweenness centrality. This finding does not undervalue the role of mining in BU emergence, but rather suggests that the core themes need to be examined as an interconnected package of factors and relationships. These thematic relationships do not imply causality but bidirectional feedback processes and connections. 
$\rightarrow$ Table 2

\section{Discussion}

Our situated knowledge approach to BU prevalence and emergence in Ghanaian gold mining communities, both endemic and non-endemic, yielded noteworthy insights on people's understandings of possible BU risk factors and exposure areas. It also revealed the plausible role of land disturbance in MU infection, particularly through artisanal alluvial mining, and practices and beliefs that allow people to make sense of a neglected tropical disease (NTD) wherein the mode of transmission remains unknown. Such a situated perspective provides a crucial platform for validating heterogeneous voices from community- and district-level participants in our collective learning and research project. We reflect on four important project outcomes.

First, our approach validates people's embedded knowledge of disease emergence in changing environmental and social landscapes in Ghana. Our results from the mapping activities, interviews, and discussions illustrate people's ability to grasp their changing environmental, social, and economic realities in multi-scalar dimensions, similar to the findings by GilesVernick et al. (2014) for Cameroon. The thematic networks for the endemic sites in Ghana exhibit an impressive local sense of complex relationships associated with BU. Participants had no difficulty in connecting the dots between disrupted landscapes and ecological devastation from artisanal gold mining, although they grappled with "knowing" or "understanding" a puzzle that even medical experts cannot explain. They blamed this environmental disturbance on a 
variety of factors, including the expansion of galamsey operations, the state's failure to support local miners, illegal logging, increased flooding, and expanding bodies of stagnant and/or contaminated water. Yet, the role of land disturbance from mining in BU disease dynamics remains underexplored in scholarly work, with the exception of an account by Kibadi et al. (2009) that explicitly links alluvial artisanal diamond mining with BU in Angola and the Democratic Republic of Congo, and Wu et al. (2015) for Ghana.

These bodies of water that participants identified as worrisome are precisely the areas around which many individuals organize their daily activities - their "activity spaces" or "the local areas within which people move or travel in the course of their daily activities" (Albert et al. 2000: 67). Through this conceptualization of space, based on participants' personal stories, experiences, and locally grounded sense making, we can identify micro- and meso-scale nodes of activity and potential points of contact with MU environments that link people and landscapes to the broader political economy of mining in Ghana. By listening to and drawing and walking with men and women from endemic communities, we have gained a deeper understanding of certain "hot spots"- spaces in which children play or swim, women do dishes or laundry, youth visit to engage in galamsey mining, and households dump rubbish. Men and women described how they often cross these spaces to reach agricultural plots, with men more likely to wear long pants and boots, or in which men hunt bush meat such as cane rats, locally known as grasscutters.

Participants were skilled in discerning processes in space rather than zooming in on concrete and static risk areas. Through stories of personal experiences and individual and collective sense making of changing landscapes, as subjective and incomplete these may be, they identified possible linkages that remain underexplored in excellent yet also partial analyses, e.g. on aquatic 
invertebrates in Ghana (Benbow et al. 2008) or BU risk in cultivated wetlands and altered forest landscapes in Cameroon (Landier et al. 2014).

Second, we underscore not only the valuable role of embedded, situated knowledge but the broader role of applied social science to foreground such place-based voices and experiences in discussions of complex disease emergence, particularly NTDs. The WHO, in its 2013 landmark resolution to set control targets for NTDs, aims to "cure $70 \%$ of all [BU] cases with antibiotics in all endemic countries by 2020" (cited in Bardosh 2014: 3). Some argue that such a target can only be achieved if the "neglected" status of applied social science research on NTDs is remedied (see discussion in Bardosh 2014). This requires recognition of the multiple ways in which social scientists can broaden the scope of research and educational activities in complex disease emergence and enrich debates on transmission pathways and interventions. Our situated knowledge approach points out linkages particularly around dirty/stagnant water, mining, flooding, and insects as interconnected drivers that may otherwise go unnoticed. This insight is relevant for further fine-tuning research hypotheses; yet, no published study tackles this nexus in a satisfactory, comprehensive way. We do not claim that all local knowledge is necessarily true or correct, acknowledging the danger that emanates from the trap of romanticizing indigenous knowledge. Nonetheless, we agree with findings from Cameroon (Giles-Vernick et al. 2014) that the "local" is rarely neatly and narrowly delineated. Additionally, we recognize the limitations inherent in our own knowledge. By integrating experiential knowledge, we may create a more functional, more holistic understanding of the landscape of BU emergence. 
An approach that draws upon situated knowledge coupled with participatory methods makes time to sit, engage, chat, listen, debate, draw, and play with clay, mirroring recent attempts of "slow research" (Adams et al. 2013) in global health. It also generates valuable material for navigating different types of knowing in further analysis, ranging from a woman's bodily experience with an insect bite to complex structural equation models carried out in remote data labs. Place-based accounts of environments, bodies, and disease can indeed complement presumably more objective scientific approaches, as both tend to be partial, incomplete, and sometimes contradictory. Such place-based narratives represent one way of knowing, one way of doubting, one way of grappling with reality. Yet, they are not static, or 'traditional'; they change over space and time and are shaped by cultural beliefs, landscape change, shifting environmental interactions, and external knowledge brokers, ourselves included.

Third, our approach emphasizes the role of engagement with local ways of knowing as essential for informing the research process. As Geissler (2013) demonstrates, the relationships between researcher and participant, between knowing and unknowing, are fundamental in establishing the trust and confidence that will in turn produce not only the best science but the best "knowledge". This best knowledge, in turn, increases trust, respect, and motivation in global health intervention and performance (Magrath \& Nichter 2012). By making visible marginalized forms of "knowing", we as researchers honor our relationships with community members and the integrity of our results. In our project, these relationships were further enriched by communicating across cultures, between Ghanaian and US colleagues, both at the community level and with partner primary and secondary schools. Through educational activities in schools and by reporting scientific knowledge about BU in community forums, via posters, pamphlets, 
plays, and songs, our team has also shaped understandings of BU in rural spaces. In other words, "scientific" knowledge and that of people living and working in endemic areas becomes situated and entangled in unforeseen ways, breaking down seemingly self-evident boundaries between "expert" and "local" knowledge. Other aspects of team learning created a shared space to listen and exchange between and among educators, in Ghana and the United States: learning about research practices, replicating these practices in classrooms, and discovering with students that inquiry-based science is rarely linear and entirely predictable. Analyzing complex real-world problems using iterative and complementary approaches was transformational for the teachers, demonstrating that no one knowledge is necessarily superior.

Finally, we highlight that our qualitative and situated knowledge approach is not just valuable in itself but that it also informs social-ecological modeling of BU emergence by prioritizing the forms of interactions and types of variables that are likely to matter. Rather than discussing these quantitative models here, we acknowledge that visualizing insights from situated knowledge (see Figures 3-5) enabled our team to reconsider and refine possible structural relationships and values among all candidate variables, including ecological ones (Wu et al. 2015). Rounds of conceptual discussions within our interdisciplinary team generated a unique opportunity for collaborative learning. Collaborative efforts in interdisciplinary research are often taken for granted; yet, researchers often struggle to articulate how to do it and how to be reflective (Pujidas Bothey et al. 2014). In our team, several members participated in data collection processes, described their interpretations within their discipline's paradigm, and translated their own analysis to the broader group. This iterative navigation increased the validation of diverse data sets and allowed the team to communicate across barriers, approaching the complexity of 
BU through a pluralistic lens. This pluralism is reflected in the bottom-up pathogenic landscape analysis by not imposing a hierarchy of themes relating to BU emergence; instead, it offered a complex web of knowing with dynamic direct and indirect relationships. Indeed, qualitative approaches and results aid reasoning under incomplete information (Ramsey and Veltman 2005) using all available knowledge (McIntosh 2003).

The use of qualitative data to inform quantitative models, albeit still in its infancy, is a vital area of new research. Quantitative approaches are increasingly employed to explore complex dynamics of health geography and socio-ecological landscape change. For instance, suitable modeling frameworks are informed by first understanding the structure, value and interactions of different components, and thus depend on qualitative understanding of socio-ecological relationships (McIntosh 2003). When simulated using a dynamic process model, they are grounded on a mechanistic understanding that is derived, as much as possible, from observations of bivariate relationships; in turn, emergent behavior in the model necessarily derives from the complex interactions among these relatively simple relationships. When seeking to predict and interpret complex landscape dynamics using these models, however, unexplained emergent interactions can be the norm, rather than the rule. Situated, contextualized community knowledge - in our case participants' insistence on the connection between galamsey mining, dirty/stagnant water, and biting insects - provides clues for these unexpected interactions.

\section{Conclusion}


The accounts gained from participatory mapping activities, individual interviews, and group discussions reveal a contextualized view that puts the daily reality and embodied experiences of encountering disease in a spatial context while offering a process-driven appreciation of interconnections between place, human activities, and knowledge. These approaches to qualitative research, foregrounding the voices and explanations of people living in at-risk areas, provide a vibrant and vital complementary way of knowing Buruli ulcer, a neglected tropical disease, to multi- and interdisciplinary approaches. They inform dialogic research processes and foster deliberative spaces in complex system science, epidemiology, or land-cover/land-use change science. 


\section{References:}

Ackumey, M. M., Kwakye-Maclean, C., Ampadu, E. O., de Savigny, D., \& Weiss, M. G. (2011). Health services for Buruli ulcer control: Lessons from a field study in Ghana. PLoS Negl Trop Dis, 5(6), e1187.

Adams, V., Burke, N. J., \& Whitmarsh, I. (2013). Slow research: Thoughts for a movement in global health. Medical Anthropology, 33(3), 179-197.

Ahorlu, C. K., Koka, E., Kumordzi, S., Yeboah-Manu, D., \& Ampadu, E. (2013). Social and economic factors influencing Buruli ulcer health seeking decision making in the Ga West and South Municipalities. Advances in Applied Sociology, 03(04), 187-192.

Albert, D. P., Gesler, W. M., \& Horner, R. D. (2000). Geographic information systems in health services research. In D. P. Albert, W. M. Gesler, \& B. Levergood (Eds.), Spatial Analysis, GIS and Remote Sensing Applications in the Health Sciences (pp. 55-76). CRC Press.

Allotey, P., Reidpath, D. D., \& Pokhrel, S. (2010). Social sciences research in neglected tropical diseases 1: the ongoing neglect in the neglected tropical diseases. Health Research Policy and Systems, 8(1), 32.

Ampadu, B., Chapple, N. A., \& Tych, W. (2014). DHR modelling of cycles in rainfall and riverflow across Ghana. Saarbrücken: LAP LAMBERT Academic Publishing.

Attride-Stirling, J. (2001). Thematic networks: an analytic tool for. Qualitative Research, 1(3), $385-405$.

Bardosh, K. (2014). Global aspirations, local realities: the role of social science research in controlling neglected tropical diseases. Infectious Diseases of Poverty, 3(1), 35. 
Benbow, M. E., Williamson, H., Kimbirauskas, R., McIntosh, M. D., Kolar, R., Quaye, C., ... Merritt, R. W. (2008). Aquatic invertebrates as unlikely vectors of Buruli ulcer disease. Emerging Infectious Diseases, 14(8), 1247-1254.

Benhin, J. K. A., \& Barbier, E. B. (2004). Structural adjustment programme, deforestation and biodiversity loss in Ghana. Environmental and Resource Economics, 27(3), 337-366.

Borgatti, S., Everett, M., \& Freeman, L. (2002). Ucinet for Windows: Software for social network analysis. Analytic Technologies.

Borgatti, S. P., Everett, M. G., \& Johnson, J. C. (2013). Analyzing social networks. SAGE Publications Limited.

Catley, A., Alders, R. G., \& Wood, J. L. N. (2012). Participatory epidemiology: Approaches, methods, experiences. The Veterinary Journal, 191(2), 151-160.

Cornwall, A., \& Jewkes, R. (1995). What is participatory research? Social Science \& Medicine, 41(12), 1667-1676.

Cumming, G.S., Allen, C.R., Ban, N.C., Biggs, D., Biggs, H.C., et al. (2015) Understanding protected area resilience: a multi-scale, social-ecological approach. Ecological Applications, 25(2):299-319.

Dickin, S. K., Schuster-Wallace, C. J., \& Elliott, S. J. (2014). Mosquitoes \& vulnerable spaces: Mapping local knowledge of sites for dengue control in Seremban and Putrajaya Malaysia. Applied Geography, 46, 71-79.

EM-DAT Disaster Database (2014). URL http://www.emdat.be/database [accessed July 5 2015]

Follér, M. L. (2001). Interactions between global processes and local health problems. A human ecology approach to health among indigenous groups in the Amazon. Cadernos de Saúde Pública, 17, S115-S126. 
Geissler, P. W. (2013). Public secrets in public health: Knowing not to know while making scientific knowledge. American Ethnologist, 40(1), 13-34.

Giles-Vernick, T., Owona-Ntsama, J., Landier, J., \& Eyangoh, S. (2014). The puzzle of Buruli ulcer transmission, ethno-ecological history and the end of "love" in the Akonolinga district, Cameroon. Social Science \& Medicine.

Haraway, D. (1988). Situated Knowledges: The Science question in feminism and the privilege of partial perspective. Feminist Studies, 14(3), 575.

Haraway, D. (1991). Simians, cyborgs, and women: The reinvention of women. London and New York: Routledge.

Hausermann, H., Tschakert, P., Smithwick, E. A. H., Ferring, D., Amankwah, R., Klutse, E., ... Kromel, L. (2012). Contours of risk: Spatializing human behaviors to understand disease dynamics in changing landscapes. EcoHealth, 9(3), 251-255.

Hilson, G., \& Potter, C. (2005). Structural adjustment and subsistence industry: artisanal gold mining in Ghana. Development and Change, 36(1), 103-131.

Hirons, M. (2014). Shifting sand, shifting livelihoods? Reflections on a coastal gold rush in Ghana. Resources Policy, 40, 83-89.

Kibadi, K., Boelaert, M., Kayinua, M., Minuku, J.-B., Muyembe-Tamfum, J.-J., Portaels, F., ... Lefèvre, P. (2009). Therapeutic itineraries of patients with ulcerated forms of Mycobacterium ulcerans (Buruli ulcer) disease in a rural health zone in the Democratic Republic of Congo. Tropical Medicine \& International Health, 14(9), 1110-1116. 
Lambin, E. F., Tran, A., Vanwambeke, S. O., Linard, C., \& Soti, V. (2010). Pathogenic landscapes: interactions between land, people, disease vectors, and their animal hosts. International Journal of Health Geographics, 9, 54.

Landier, J., Gaudart, J., Carolan, K., Lo Seen, D., Guégan, J.-F., Eyangoh, S., ... Texier, G. (2014). Spatio-temporal patterns and landscape-associated risk of Buruli ulcer in Akonolinga, Cameroon. PLoS Negl Trop Dis, 8(9), e3123.

Leach, M., \& Scoones, I. (2013). The social and political lives of zoonotic disease models: Narratives, science and policy. Social Science \& Medicine, 88, 10-17.

Magrath, P., \& Nichter, M. (2012). Paying for performance and the social relations of health care provision: an anthropological perspective. Social Science \& Medicine, 75(10), 1778-1785.

McIntosh, B.S. (2003) Qualitative modelling with imprecise ecological knowledge: a framework for simulation. Environmental Modelling \& Software, 18(4):295-307.

McIntosh, M., Williamson, H., Benbow, M. E., Kimbirauskas, R., Quaye, C., Boakye, D., ... Merritt, R. (2014). Associations between Mycobacterium ulcerans and aquatic plant communities of West Africa: Implications for Buruli ulcer disease. EcoHealth, 11(2), 184196.

Merritt, R. W., Walker, E. D., Small, P. L. C., Wallace, J. R., Johnson, P. D. R., Benbow, M. E., ... Boakye, D. A. (2010). Ecology and transmission of Buruli ulcer disease: A systematic review. PLoS Neglected Tropical Diseases, 4(12), e911.

Nichter, M. (1987). Kyasanur forest disease: An ethnography of a disease of development. Medical Anthropology Quarterly, 1(4), 406-423.

Nygren, A. (1999). Local Knowledge in the Environment-Development Discourse From dichotomies to situated knowledges. Critique of Anthropology, 19(3), 267-288. 
Patz, J. A., Daszak, P., Tabor, G. M., Aguirre, A. A., Pearl, M., Epstein, J., ... Bradley, D. J. (2004). Unhealthy landscapes: Policy recommendations on land use change and infectious disease emergence. Environmental Health Perspectives, 112(10), 1092-1098.

Portaels, F., Silva, M. T., \& Meyers, W. M. (2009). Buruli ulcer. Clinics in Dermatology, 27(3), 291-305.

Pujadas Botey, A., Garvin, T., \& Szostak. R. (2014).Interdisciplinary Research for Ecosystem Management. Ecosystems, 17(3):512-21.

Ramsey, D., \& Veltman, C. (2005). Predicting the effects of perturbations on ecological communities: what can qualitative models offer? Journal of Animal Ecology, 74(5):905-16.

Rosecrans, K., Cruz-Martin, G., King, A., \& Dumonteil, E. (2014). Opportunities for improved Chagas disease vector control based on knowledge, attitudes and practices of communities in the Yucatan peninsula, Mexico. PLoS Neglected Tropical Diseases, 8(3), e2763.

Trostle, J. A., \& Sommerfeld, J. (1996). Medical anthropology and epidemiology. Annual Review of Anthropology, 253-274.

Tschakert, P., \& Singha, K. (2007). Contaminated identities: mercury and marginalization in Ghana's artisanal mining sector. Geoforum, 38(6), 1304-1321.

Van Ravensway, J., Benbow, M. E., Tsonis, A. A., Pierce, S. J., Campbell, L. P., Fyfe, J. A. M., ... Qi, J. (2012). Climate and landscape factors associated with Buruli ulcer incidence in Victoria, Australia. PLoS ONE, 7(12), e51074.

Williamson, H. R., Mosi, L., Donnell, R., Aqqad, M., Merritt, R. W., \& Small, P. L. C. (2014). Mycobacterium ulcerans fails to infect through skin abrasions in a guinea pig infection model: Implications for Transmission. PLoS Negl Trop Dis, 8(4), e2770. 
Willson, S. J., Kaufman, M. G., Merritt, R. W., Williamson, H. R., Malakauskas, D. M., \& Benbow, M. E. (2013). Fish and amphibians as potential reservoirs of Mycobacterium ulcerans, the causative agent of Buruli ulcer disease. Infection Ecology \& Epidemiology, 3.

World Health Organization (WHO) (2012). Global Report for Research on Infectious Diseases of Poverty. Geneva, Switzerland.

World Health Organization (WHO) (2013). Number of new Buruli ulcer cases reported in 2013. http://apps.who.int/neglected_diseases/ntddata/buruli/buruli.html [accessed July 5 2015] World Health Organization (WHO) (2014). Buruli ulcer: Fact sheet 2014. URL http://www.who.int/mediacentre/factsheets/fs199/en/ [accessed July 5 2015]

Wu, J., Tschakert, P., Klutse, E., Ferring, D., Ricciardi, V., Hausermann, H., Oppong, J., \& Smithwick, E. (2015) Buruli Ulcer Disease and Its Association with Land Cover in Southwestern Ghana. PLoS Neglected Tropical Diseases 9(6): e0003840. 


\section{5-2009 Buruli Ulcer Prevalence in Ghana}

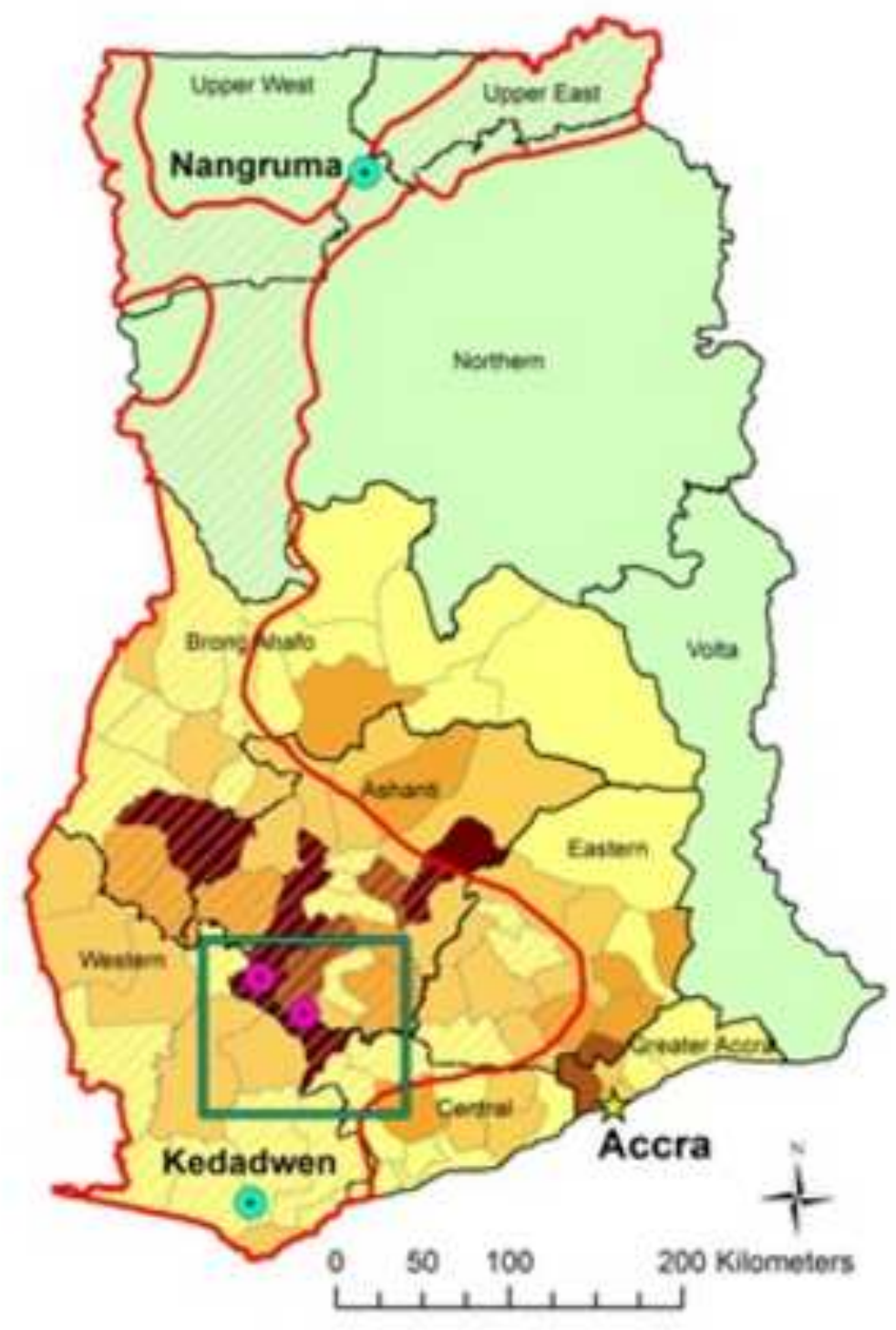

Rates per 100,000

0

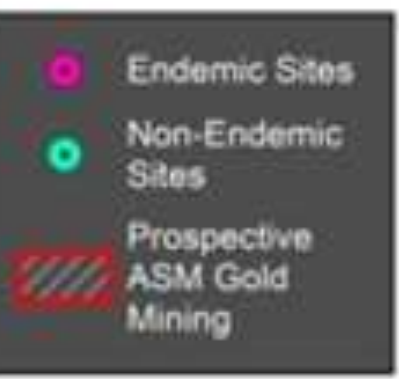

$1-4$

$5-14$

$15-40$

$41-143$

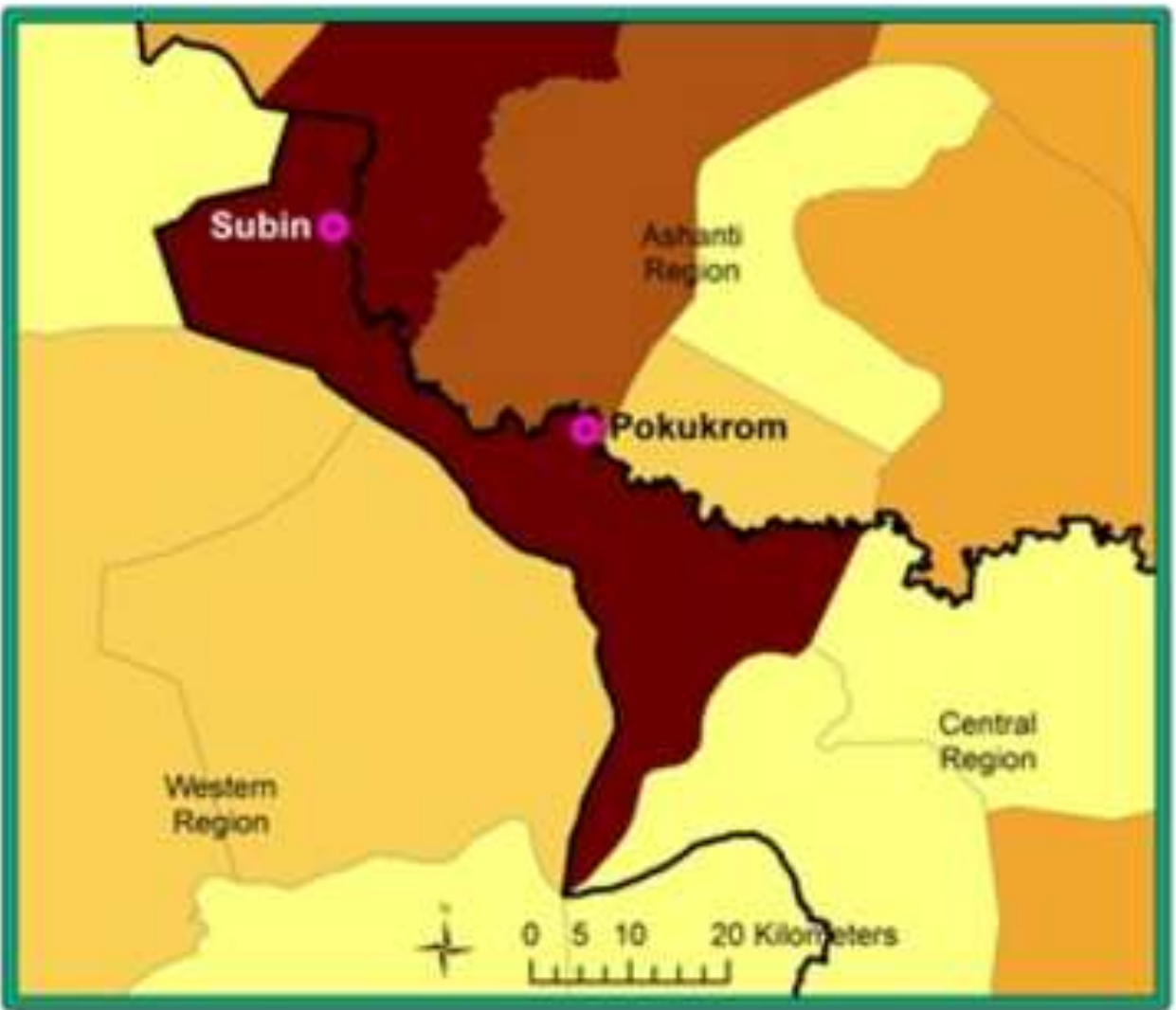

Data sources: Klutse, 2010 (unpublished raw data); Hilson, G., 2001. A Contextual Review of the Ghanalan Small-scale Mining Industry. International Institute for Environment and Development, London, England. 


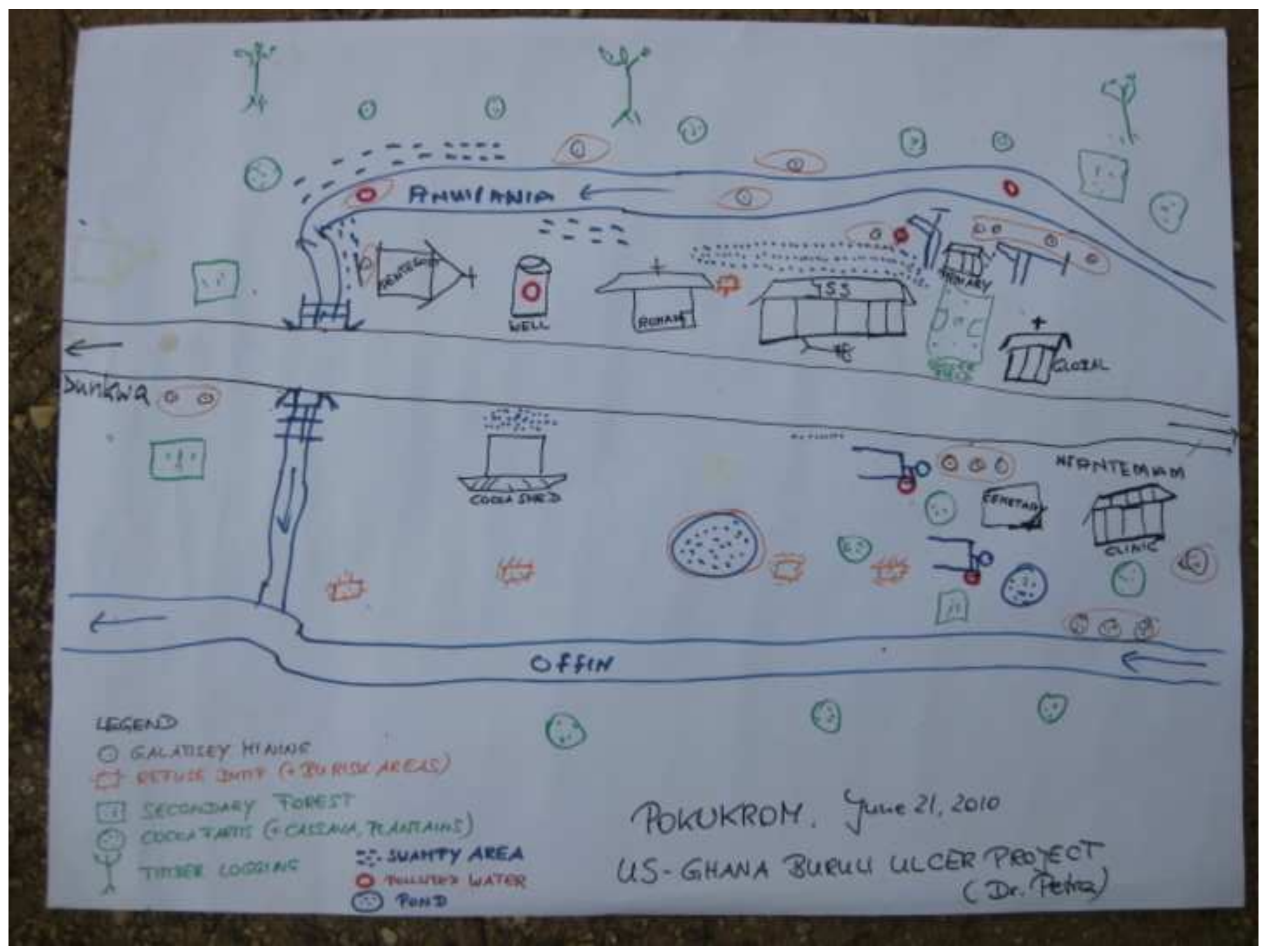


Figures (NO AUTHOR DETAILS)

\section{resulid}

\section{Pokokrom}

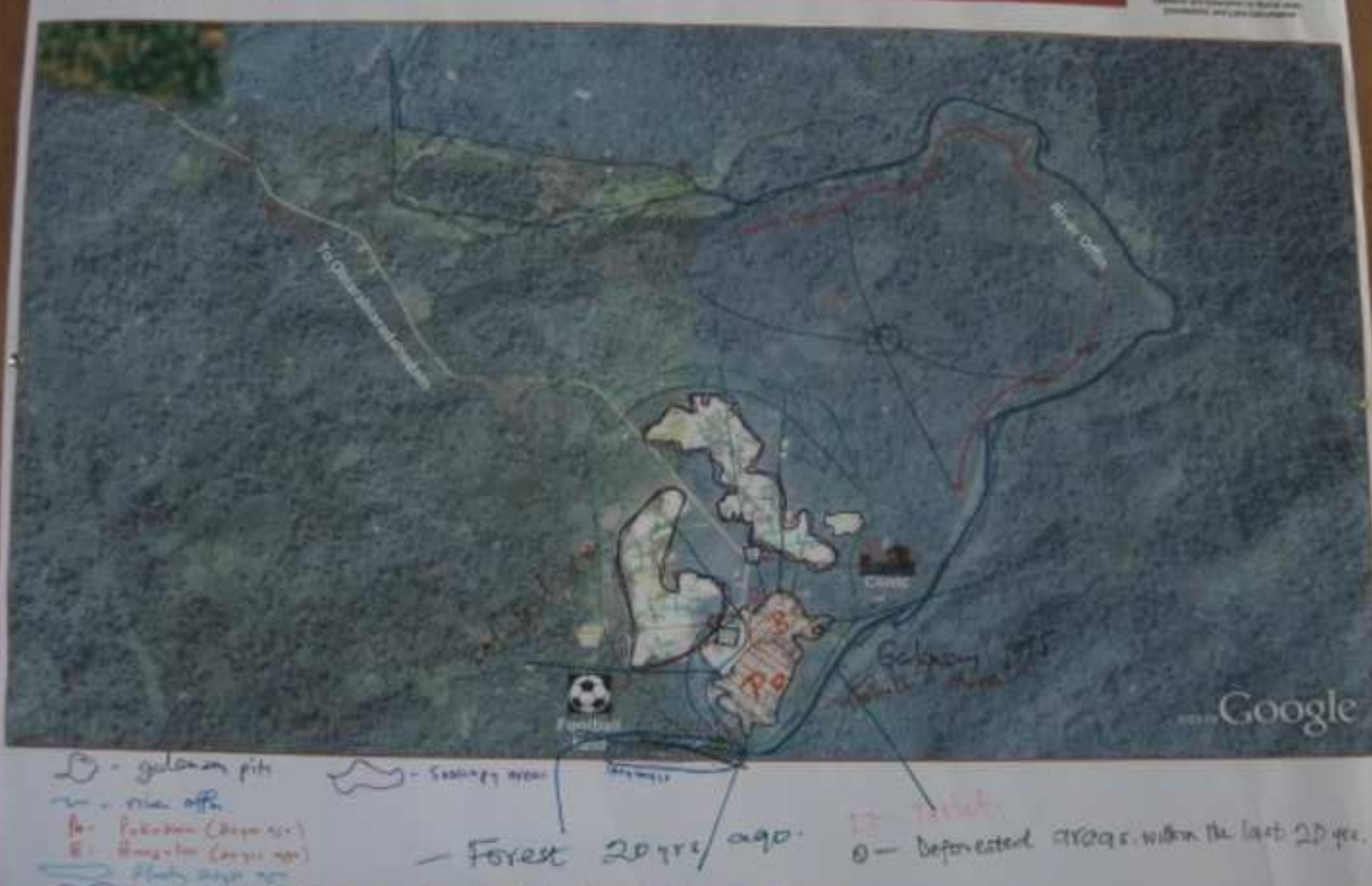



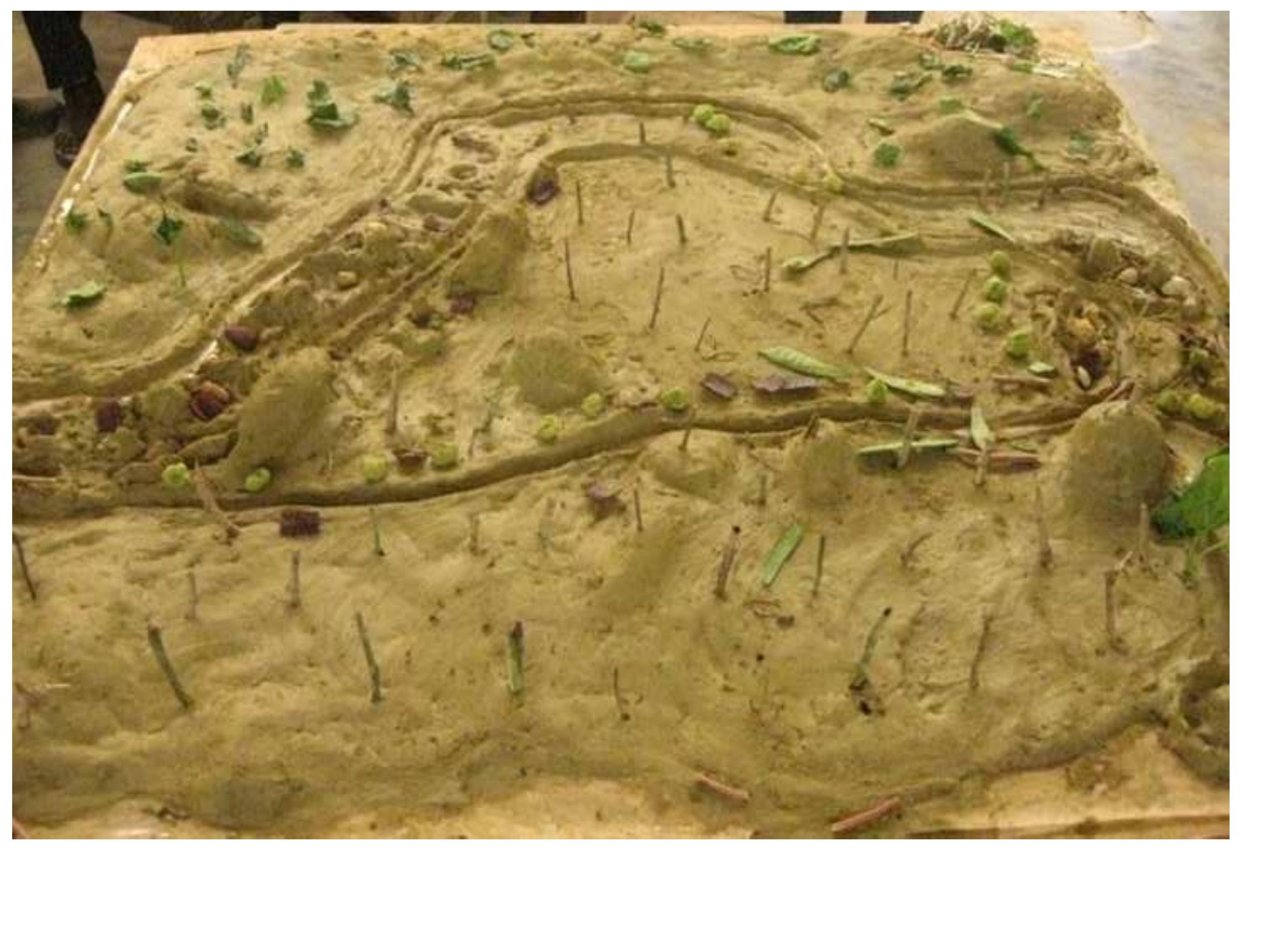


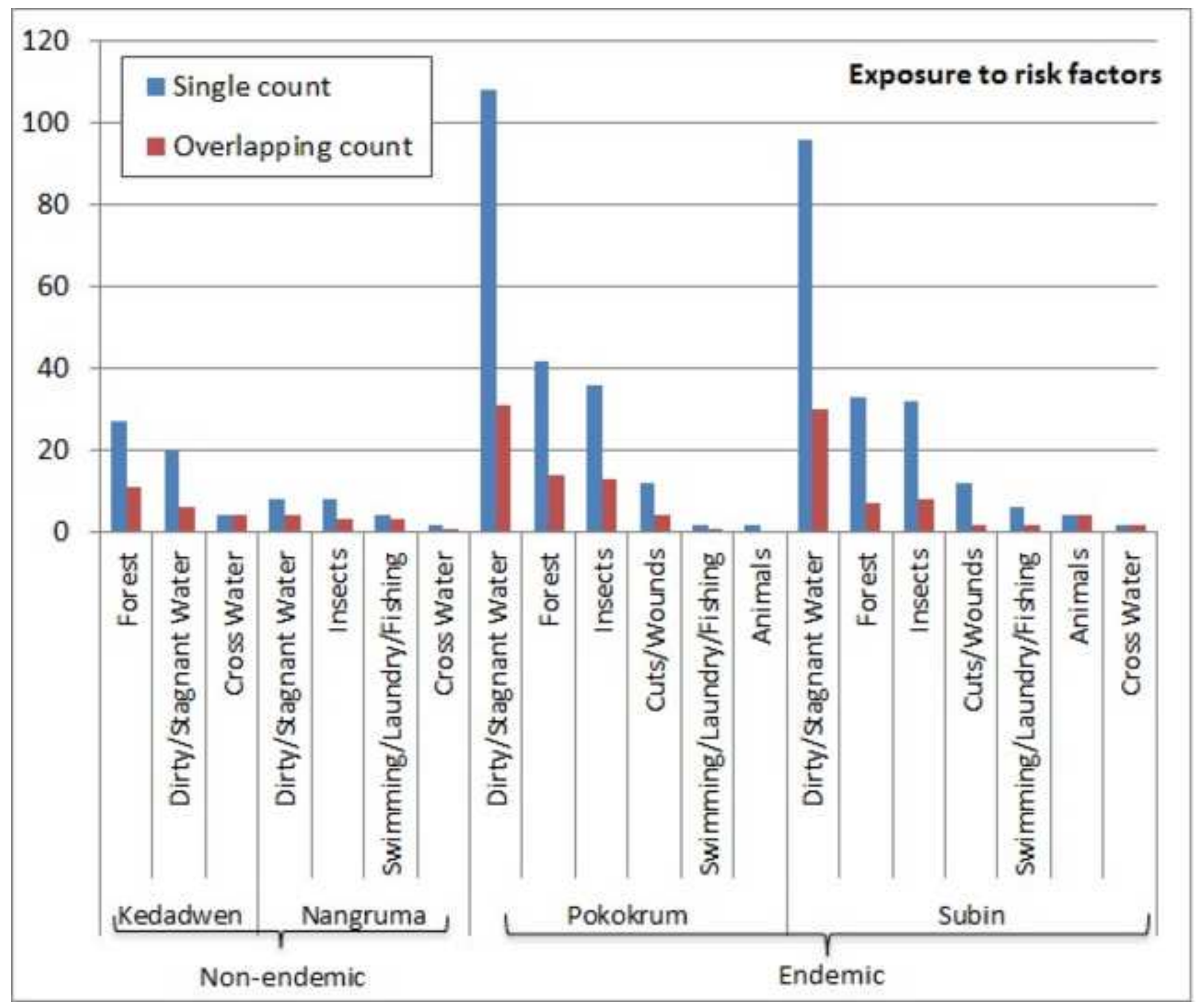




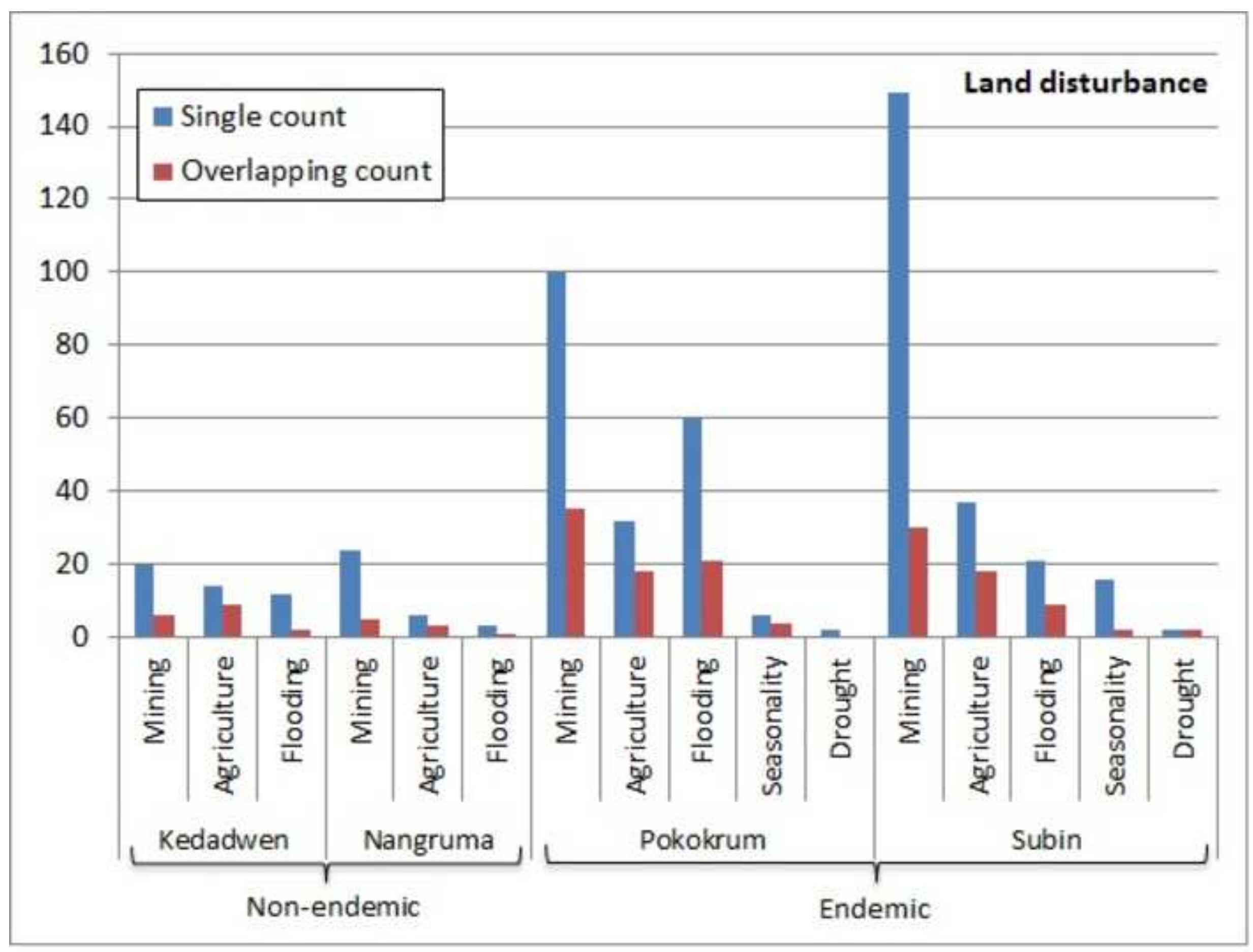




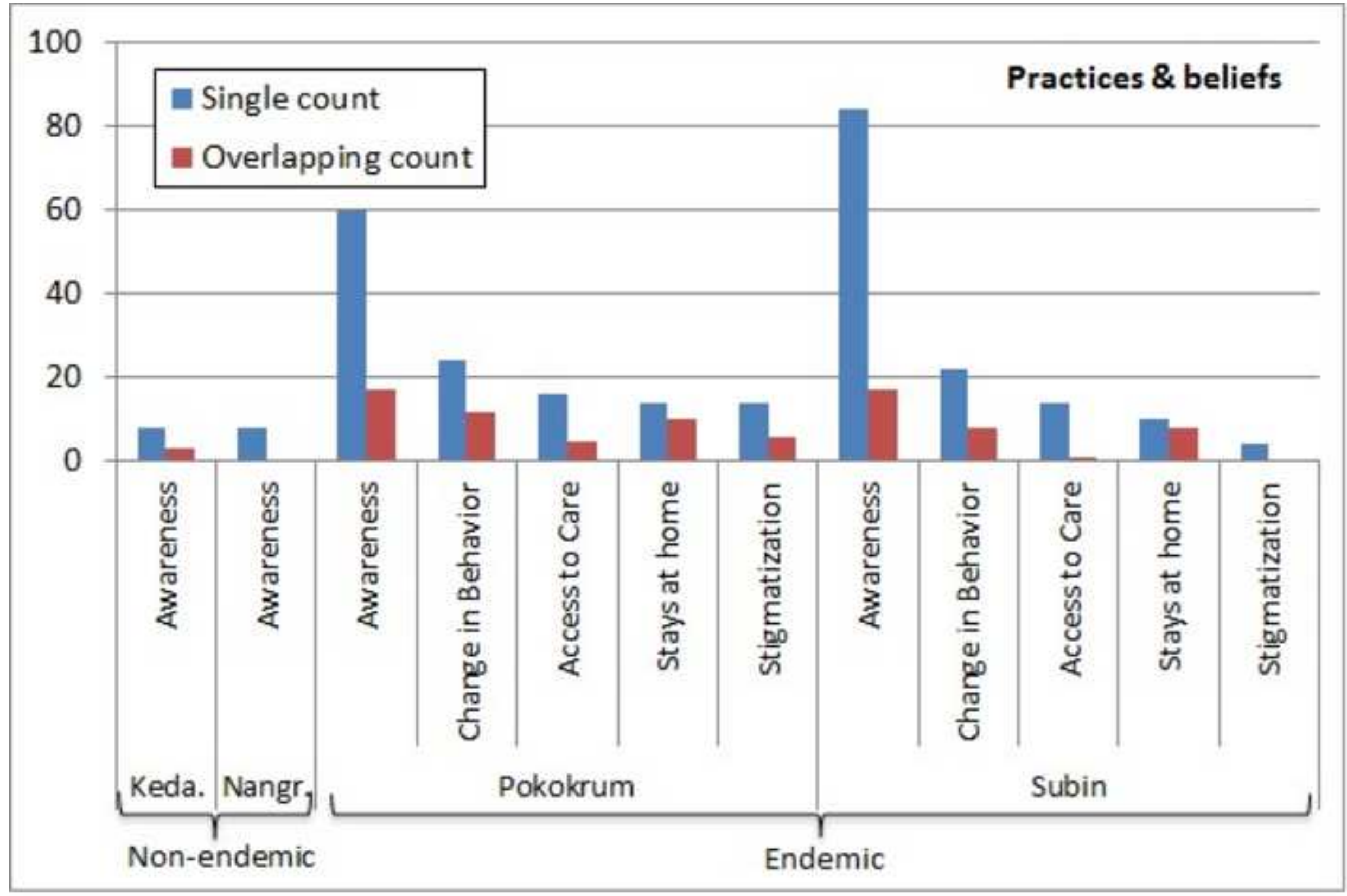




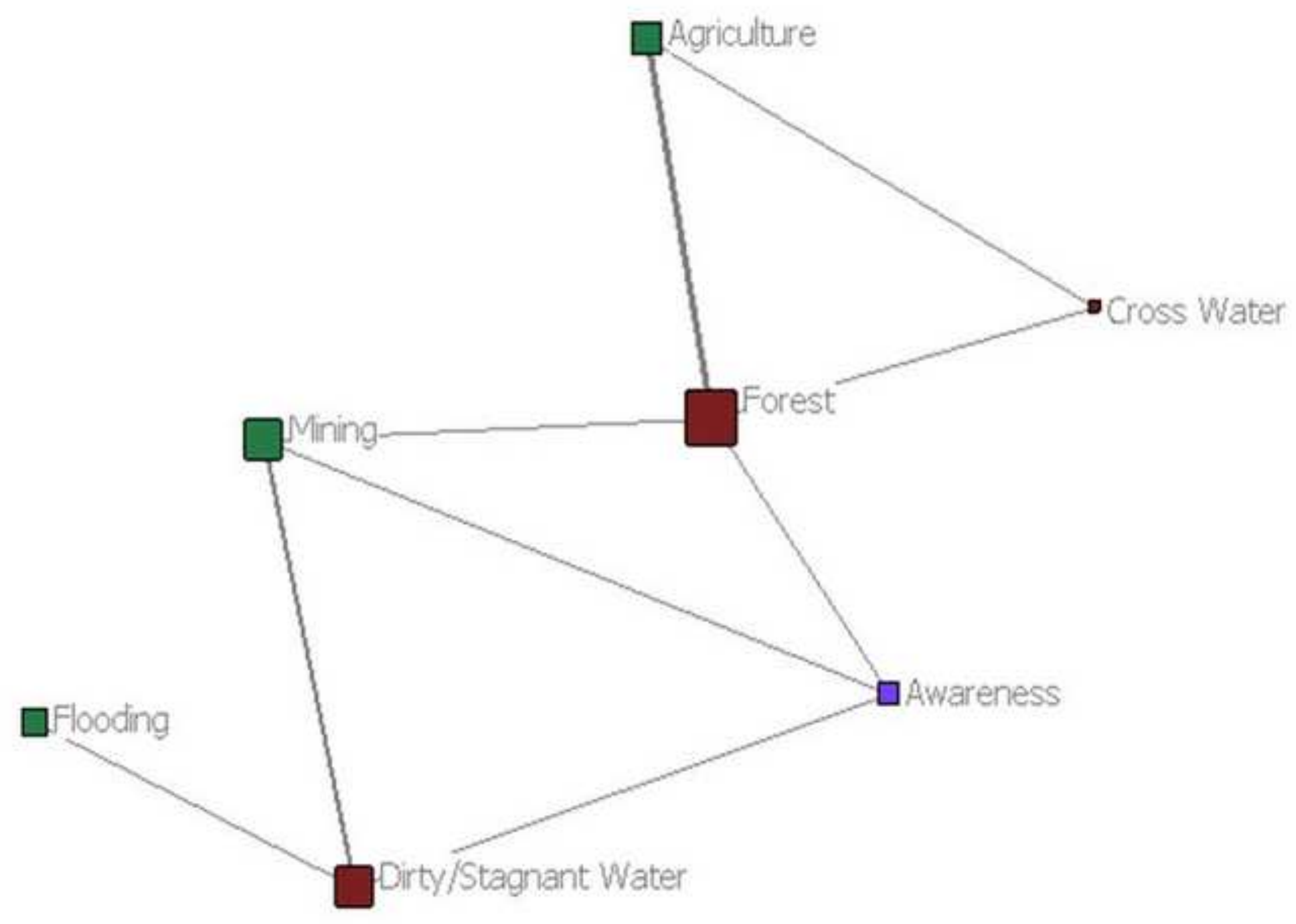


Figures (NO AUTHOR DETAILS)

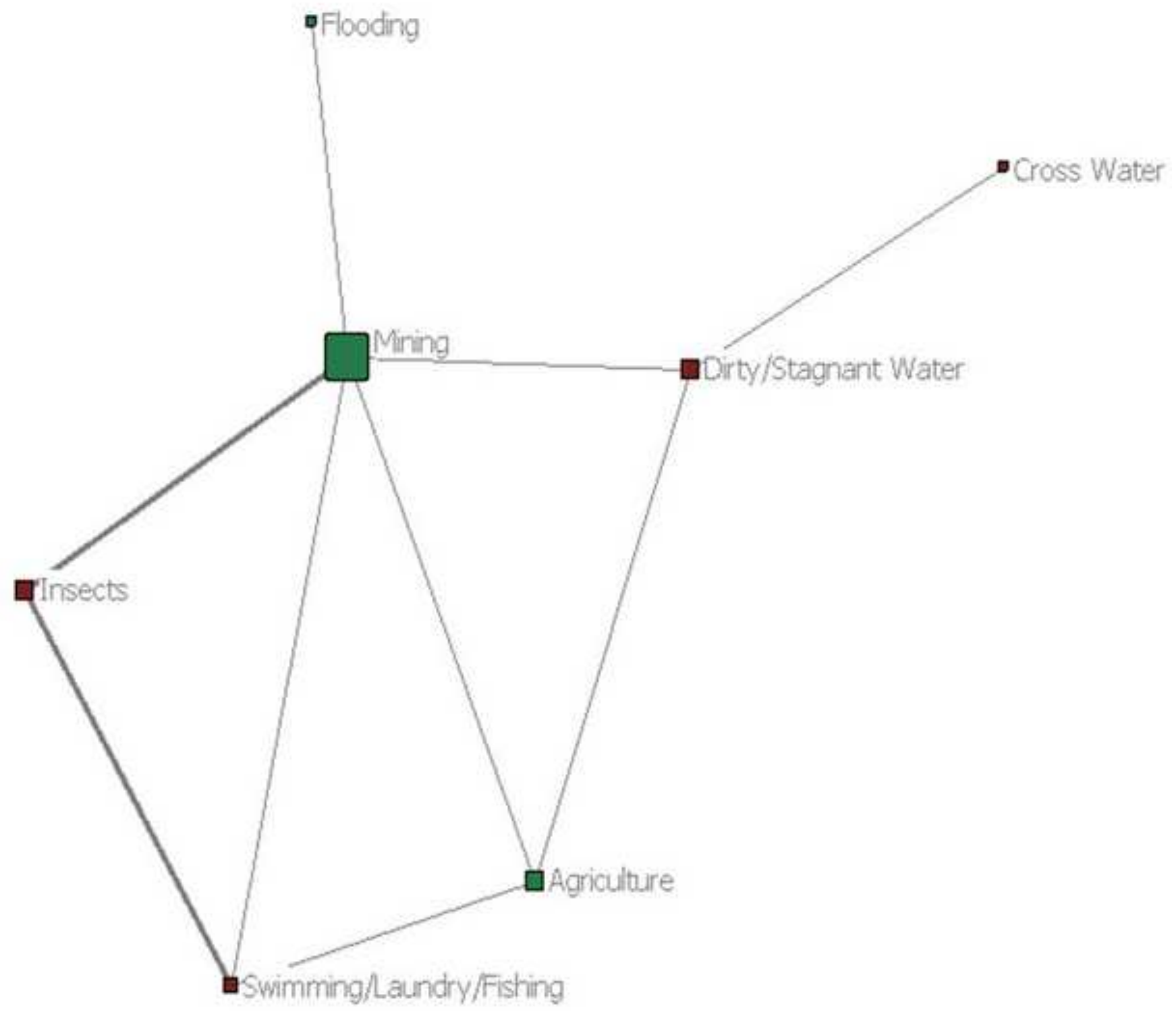


Figures (NO AUTHOR DETAILS)

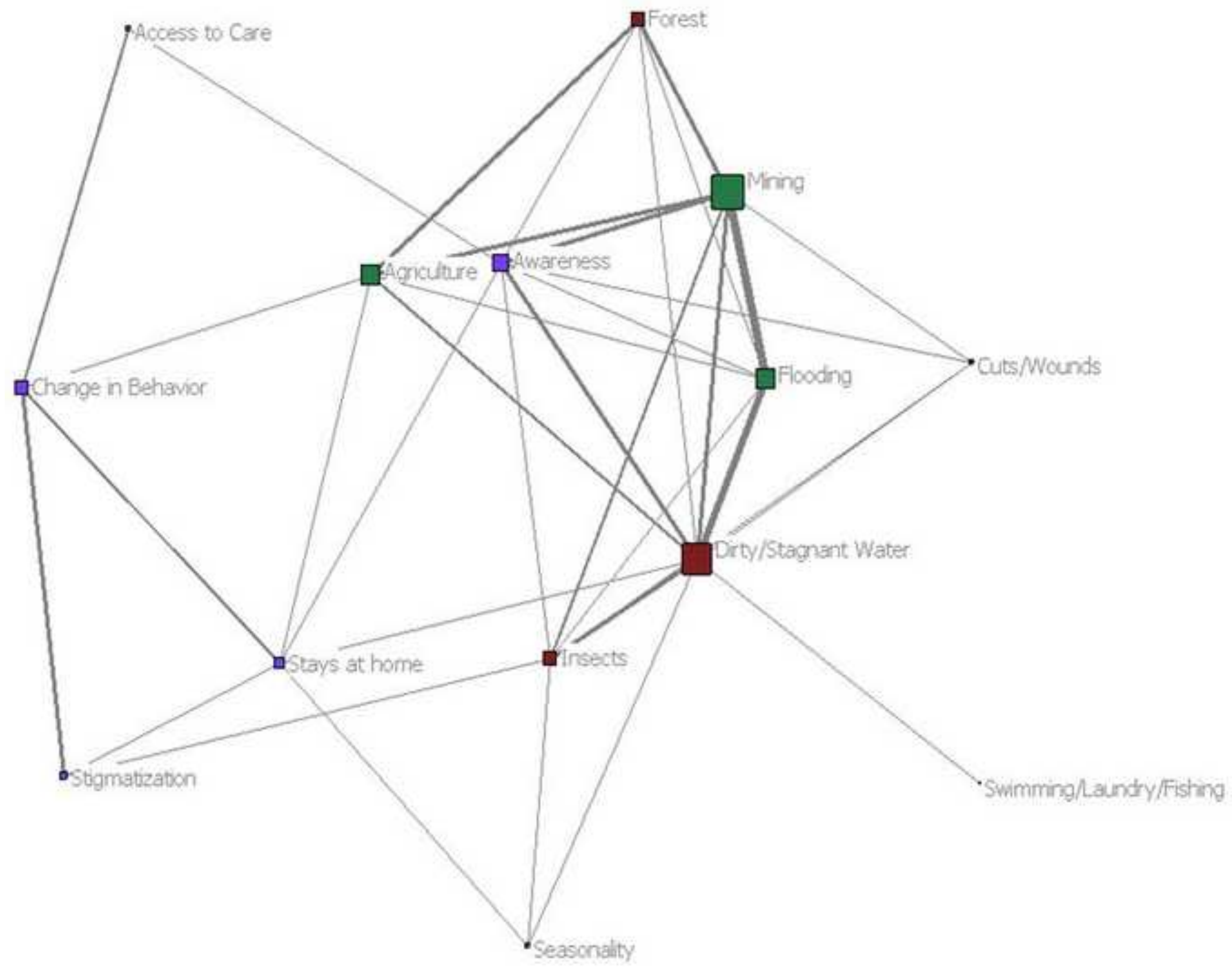


Figures (NO AUTHOR DETAILS)

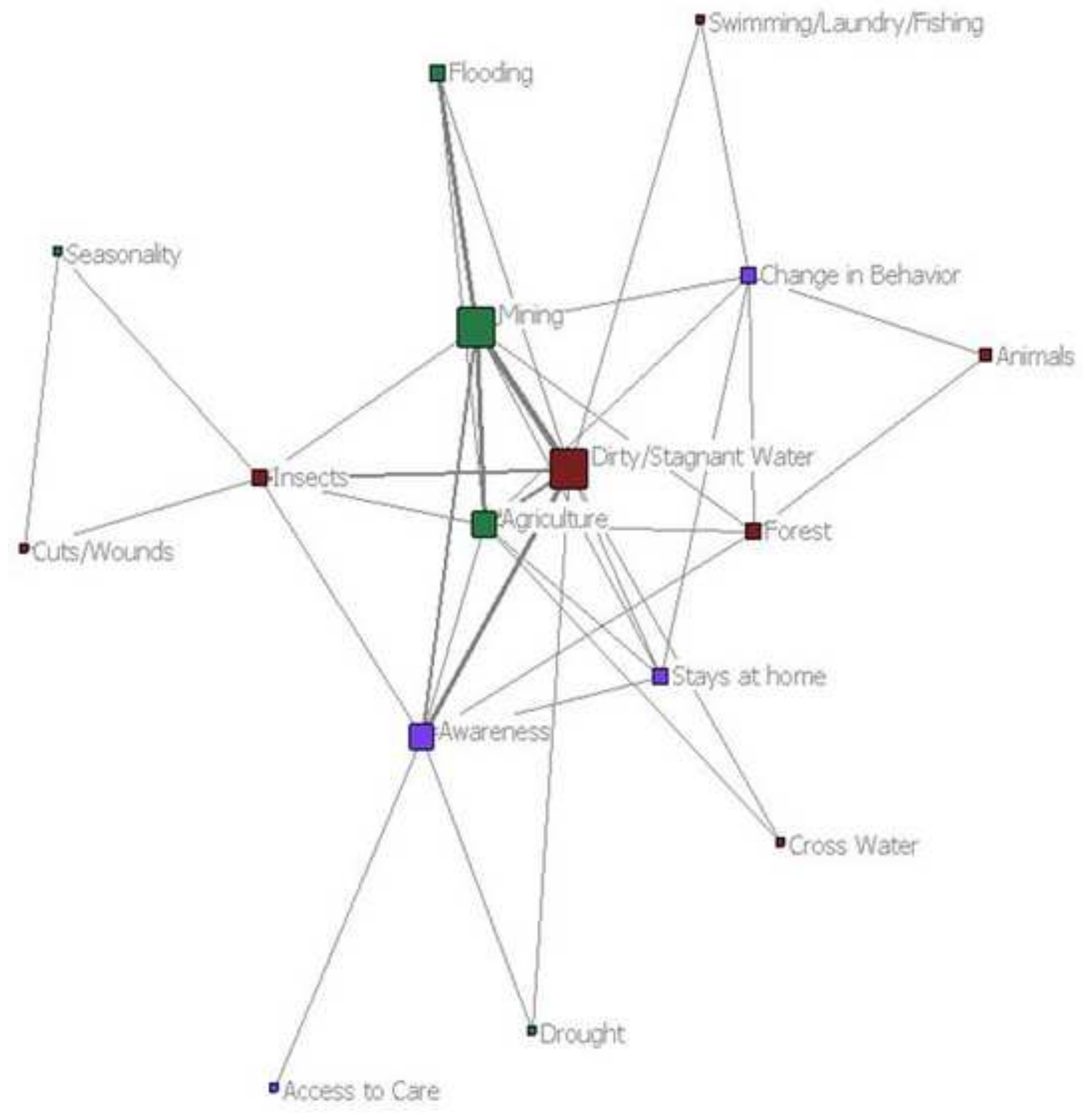




Legend
Exposure/Risk
Landscape Dis turbance
Practices and Beliefs
Size of lines is a function of the shared evidence between each theme.
Size of the nodes is a function of how much evidence supports that theme.




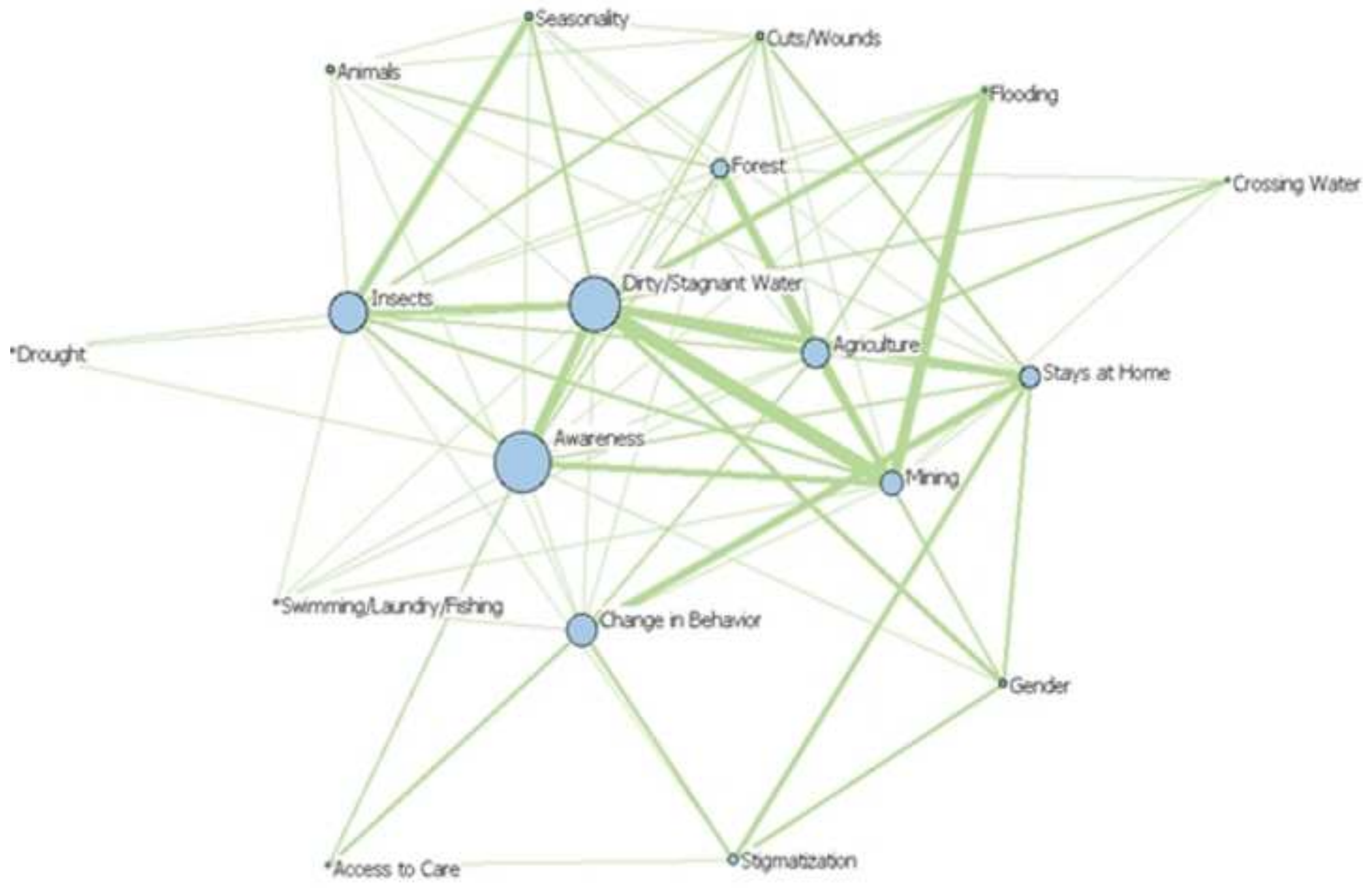




\section{Tables:}

Table 1: Overview of activities and number of participants for this sub-part of the research project. Population sizes are based on the 2010 Ghana Population and Housing Census (except Nangruma) and include satellite hamlets for Pokukrom and Subin. $\mathrm{F}=$ female, $\mathrm{M}=$ male.

\begin{tabular}{|c|c|c|c|c|}
\hline & \multicolumn{2}{|c|}{ Endemic } & \multicolumn{2}{|c|}{ Non-endemic } \\
\hline & Pokukrom & Subin & Kedadwen & Nangruma \\
\hline Population size & 1,250 & 2,240 & 1,170 & $\sim 400$ \\
\hline Infrastructure & School, clinic & School, clinic & School & School \\
\hline \multicolumn{5}{|l|}{ Activities: } \\
\hline Participatorty community mapping, 2010 & $13(\mathrm{~F}+\mathrm{M})$ & $18(\mathrm{~F}+\mathrm{M})$ & $13(\mathrm{~F}+\mathrm{M})$ & $9(\mathrm{~F}+\mathrm{M})$ \\
\hline \multicolumn{5}{|l|}{ [large sheet of papers, markers, 2-3 hrs] } \\
\hline Participatorty mapping historical land use, 2011 & $\sim 20(\mathrm{~F}+\mathrm{M})$ & $\sim 25(\mathrm{~F}+\mathrm{M})$ & $15(\mathrm{~F}+\mathrm{M})$ & $8(\mathrm{~F}+\mathrm{M})$ \\
\hline [large print-outs of maps, markers, 2-3 hrs] & Google map & Google map & Local map & Google map \\
\hline Participatory 3D landscape model, 2012 & $\sim 25(\mathrm{~F}+\mathrm{M})$ & $\sim 30(\mathrm{~F}+\mathrm{M})$ & No & No \\
\hline \multicolumn{5}{|l|}{ [in schools, with clay on plywood, $3 \mathrm{hrs]}$} \\
\hline Open-response questions, BU cases, 2010-13 & $9(6 \mathrm{~F}, 3 \mathrm{M})$ & $7(3 \mathrm{~F}, 4 \mathrm{M})$ & N/a & N/a \\
\hline \multicolumn{5}{|l|}{ [at the end of a detailed survey, 10-15 min] } \\
\hline Short semi-structured interviews, 2013 & $3(3 \mathrm{~F}, 0 \mathrm{M})$ & $3(1 \mathrm{~F}, 2 \mathrm{M})$ & N/a & N/a \\
\hline \multicolumn{5}{|l|}{ [six follow-up questions, $B U$ cases, $30 \mathrm{~min}]$} \\
\hline Focus group discussion, 2013 & $5(4 \mathrm{~F}, 1 \mathrm{M})$ & $8(4 \mathrm{~F}, 4 \mathrm{M})$ & N/a & N/a \\
\hline [with BU volunteers, health staff, $1-1.5 \mathrm{hr}$ ] & & & & \\
\hline
\end{tabular}


Table 2: Centrality measures indicating how each theme is central. The degree centrality refers to how many connections each theme has to other themes. Betweenness measures if a theme is on the shortest path between all other themes and was used to identify which themes explain the indirect linkage between two themes without assuming causality.

\begin{tabular}{|c|c|c|c|c|c|c|c|c|c|c|c|c|c|c|c|c|}
\hline \multirow[b]{4}{*}{ Land Disturbance } & \multirow{2}{*}{\multicolumn{8}{|c|}{ Non-Endemic }} & \multirow{2}{*}{\multicolumn{8}{|c|}{ Endemic }} \\
\hline & & & & & & & & & & & & & & & & \\
\hline & \multicolumn{4}{|c|}{ Kedadwen } & \multicolumn{3}{|c|}{ Nangruma } & & \multicolumn{3}{|c|}{ Pokokrum } & & \multicolumn{3}{|c|}{ Subin } & \\
\hline & & & & & & & & & & & & & & & & \\
\hline Agriculture & 2 & 0.0 & 0.1 & 0.5 & 3 & 1.0 & 0.1 & 0.8 & 6 & 5.6 & 0.1 & 0.7 & 9 & 16.8 & 0.0 & 1.0 \\
\hline Drought & - & - & - & - & - & - & - & - & - & - & - & - & 2 & 0.0 & 0.0 & 0.3 \\
\hline Flooding & 2 & 6.0 & 0.1 & 0.3 & 1 & 0.0 & 0.1 & 0.3 & 6 & 0.9 & 0.1 & 0.8 & 3 & 0.0 & 0.0 & 0.5 \\
\hline Mining & 3 & 4.5 & 0.1 & 0.9 & 5 & 8.5 & 0.1 & 1.0 & 7 & 2.2 & 0.1 & 0.8 & 8 & 9.8 & 0.0 & 1.0 \\
\hline Seasonality & - & - & - & - & - & - & - & - & 3 & 0.3 & 0.0 & 0.4 & 2 & 0.0 & 0.0 & 0.1 \\
\hline \multicolumn{17}{|l|}{ Exposure/Risks } \\
\hline Animals & - & - & - & - & - & - & - & - & - & - & - & - & 2 & 0.0 & 0.0 & 0.2 \\
\hline Cross Water & 2 & 0.0 & 0.1 & 0.5 & 1 & 0.0 & 0.1 & 0.2 & - & - & - & - & 2 & 0.0 & 0.0 & 0.3 \\
\hline Cuts/Wounds & - & - & - & - & - & - & - & - & 4 & 0.0 & 0.0 & 0.6 & 2 & 0.0 & 0.0 & 0.1 \\
\hline Dirty/Stagnant Water & 3 & 10.0 & 0.1 & 0.8 & 3 & 5.0 & 0.1 & 0.6 & 10 & 19.8 & 0.1 & 1.0 & 9 & 21.8 & 0.0 & 0.9 \\
\hline Forest & 4 & 10.0 & 0.1 & 1.0 & - & - & - & - & 5 & 0.2 & 0.0 & 0.7 & 5 & 7.9 & 0.0 & 0.6 \\
\hline Insects & 1 & 0.0 & 0.0 & 0.2 & 2 & 0.0 & 0.1 & 0.6 & 7 & 8.0 & 0.1 & 0.8 & 6 & 26.0 & 0.0 & 0.7 \\
\hline Swimming/Laundry/Fishing & - & - & - & - & 3 & 0.5 & 0.1 & 0.8 & 1 & 0.0 & 0.0 & 0.2 & 2 & 0.5 & 0.0 & 0.2 \\
\hline \multicolumn{17}{|l|}{ Practices and Beliefs } \\
\hline Access to Care & - & - & - & - & - & - & - & - & 2 & 0.7 & 0.0 & 0.2 & 1 & 0.0 & 0.0 & 0.1 \\
\hline Awareness & 3 & 4.5 & 0.1 & 0.9 & - & - & - & - & 8 & 11.4 & 0.1 & 0.9 & 8 & 22.6 & 0.0 & 0.9 \\
\hline Change in Behavior & - & - & - & - & - & - & - & - & 4 & 3.4 & 0.0 & 0.3 & 6 & 8.5 & 0.0 & 0.6 \\
\hline Gender & - & - & - & - & - & - & - & - & - & - & - & - & - & - & - & - \\
\hline Stays at home & - & - & - & - & - & - & - & - & 6 & 7.2 & 0.1 & 0.5 & 5 & 1.1 & 0.0 & 0.7 \\
\hline Stigmatization & - & - & - & - & - & - & - & - & 3 & 1.4 & 0.0 & 0.3 & - & - & - & - \\
\hline \multicolumn{17}{|l|}{ Network level statistics } \\
\hline Average Degree & 2.5 & & & & 2.6 & & & & 5.1 & & & & 4.5 & & & \\
\hline Density & 0.4 & & & & 0.4 & & & & 0.4 & & & & 0.3 & & & \\
\hline Avg Distance & 2.3 & & & & 1.7 & & & & 1.7 & & & & 2.0 & & & \\
\hline SD Distance & 1.2 & & & & 0.7 & & & & 0.6 & & & & 0.8 & & & \\
\hline
\end{tabular}

